\title{
Experimental verification of the regulated vibration on the subsoil
}

\author{
Jaroslav Kašpárek ${ }^{1}$, Miroslav Škopán ${ }^{2}$ \\ Brno University of Technology, Institute of Automotive Engineering, Technická 2896/2, \\ Brno, Czech Republic \\ ${ }^{1}$ Corresponding author \\ E-mail: ${ }^{1}$ kasparek@fme.vutbr.cz, ${ }^{2}$ skopan@fme.vutbr.cz
}

Received 6 September 2017; accepted 15 September 2017

DOI https://doi.org/10.21595/vp.2017.19061

Check for updates

Abstract. This paper considers the influence of the change of the inclination angle of the directed compaction force on the quality of the vibrated subsoil. To determine the quality and intensity of the compacted soil the absolute and relative methods of measurement are used. During the experimental measurement the quantities, from which the compaction effect of the vibratory roller on the subsoil can be determined, were monitored. The physical properties of the subsoil also influence the quality of the compacted subsoil.

Keywords: vibratory roller, directed vibration, soil, horizontal acceleration, vertical acceleration.

\section{Introduction}

The trend of the developing technology of the vibration for the vibration technique is not preferred. The vibration exciter with undirected circular vibration (Fig. 1(b)) or the oscillation vibration (Fig. 1(c)) is enforced in terms of the construction and physical simplicity. On the contrary, the vibration exciter with the directed vibration of the compaction force (Fig. 1(a)) is a more complex construction, but its physical principle can be precisely described and its regulation is also continuous $[1,2]$. The principle is to tilt the vibration exciter with the directed vibration force vector from a position in which the force vector acts in a range from the direction of the vertical to the horizontal position of the compacted surface $[2,3]$. Since the absolute coordinated system relates to the compacted surface, the compaction effect of the force is defined by two components, vertical and horizontal. The vertical component of the force affects the intensity and depth of compaction. The horizontal component only causes the roller to slip over the surface, and its compaction effect is given by the rubbing of the tread on the surface of the compacted layer.
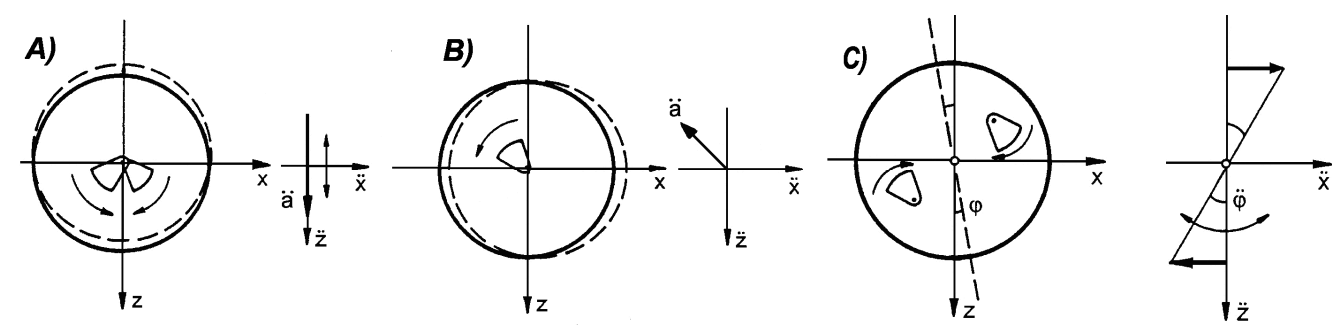

Fig. 1. Vibration exciter with: a) the directed vibration;

b) the undirected vibration (circular); c) the oscillation vibration $[2,3]$

\section{The assessment of the subsoil compaction quality}

To determine the intensity and quality of compaction two different methods are used - relative and absolute. The relative methods inform about the relative compaction quality, which means that the system measures and compares the differences in the values measured in two consecutive compaction trips.

The absolute methods determine the overall compaction rate. These are identified values of taken samples (boreholes), the evaluation of which is subject to standardized procedures. For 
illustration, a list of methods or methodologies for assessing and determining the compaction quality and intensity used by leading vibration technicians is provided [2]:

- ACE: AMMANN Compaction Expert [3-5];

- BTM-E: Bomag Terrameter - Electronic [2, 5];

- BVC: BOMAG VARIOCONTROL [2, 5];

- CCC: Continuous Compaction Control [1, 2, 3];

- CMV: Compaction Meter Value [1, 3, 4];

- OMV: Oscillometer Value [2, 3];

- RMV: Resonant Meter Value [2-4].

\section{The experimental measurement of the compaction effect of the roller with the directed vibration force vector}

For the experimental verification of the compaction effect a vibratory roller VV 1500D was provided (Fig. 2). The roller was equipped with the prototype of the vibrating drum with the directed vibration vector. The basic parameters of the machine are the operating parameters of the VV 1500 D vibratory roller with directed vibration as described in the manual [2]. These include, for example, the operating weight of $14380 \mathrm{~kg}$, the vibration amplitude of $2 \mathrm{~mm}$, the vibration frequency of $29 \mathrm{~Hz}$, the centrifugal force of $325 \mathrm{kN}$.

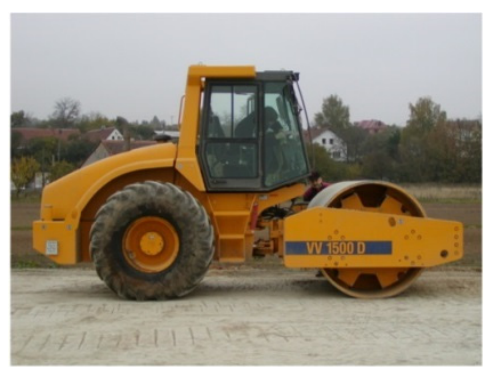

a)

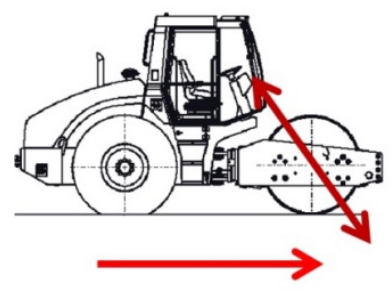

b)

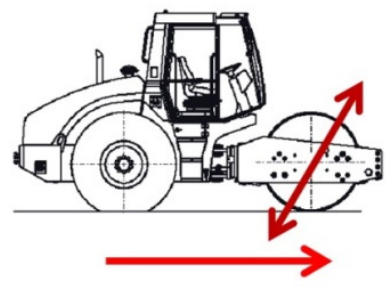

c)

Fig. 2. a) The view of the VV 1500D single drum vibratory roller,

b) convex compaction movement, c) non-convex compaction movement [2]

\section{Measurement equipment and measurement methodology}

The VV 1500 D vibratory roller contained a prototype of the regulated mechanism of the controlled vibration. The prototype of the controlled automat was produced by ECM, s.r.o. Brno. The BMC Messtechnik measuring system (16 - channel AD converter meM - ADf) and NextView/NT software version 3.4 were used to collect data from the experiment.

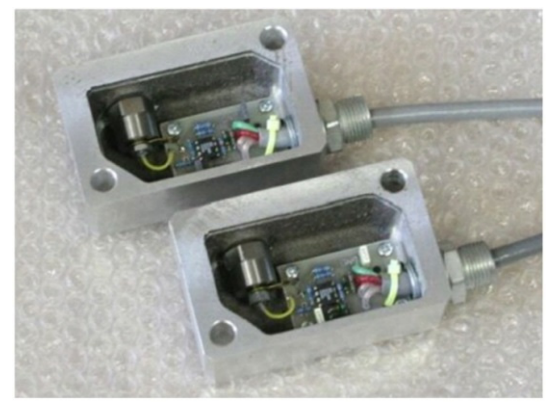

a)

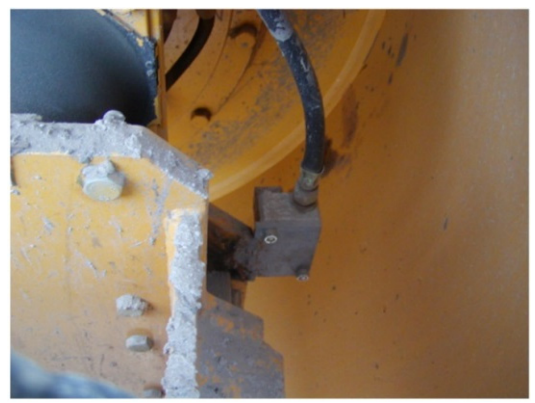

b)

Fig. 3. a) The sensor MH 128 with the amplitude amplifier, b) its application [2] 
The analog signal of the scanned channels was recorded by an MH 128 scanner with a charge amplifier from ECM, s.r.o. Brno (Fig. 3(a)) to the A/D converter with a maximum sampling frequency of $10 \mathrm{kHz}$. From there, the digitized samples were connected with a USB to the notebook, and by using the measuring software NextView/NT 3.4 they were recorded on the hard disc. Regarding the expected dynamic behavior of the process, the maximum possible sampling frequency of $2500 \mathrm{~Hz}$ was chosen, which allowed the analysis of the higher harmonic components. The analyzed signals were subjected to digital filtration by a Butterworth filter of the 8th order, with a low pass at an upper frequency of $140 \mathrm{~Hz}$ and the lower one with a limit frequency of $5 \mathrm{~Hz}$ [2]. The purpose of this filtration is in particular to smooth out the course of signals from the noise.

\section{The experimental verification}

The experimental verification was performed on a soil layer on several test fields (Fig. 4). The thickness of the compacted soil layer was about $50 \mathrm{~cm} \mathrm{[2].} \mathrm{The} \mathrm{material} \mathrm{of} \mathrm{the} \mathrm{layer} \mathrm{was} \mathrm{mined}$ gravel containing grain, sand, gravel and stones.

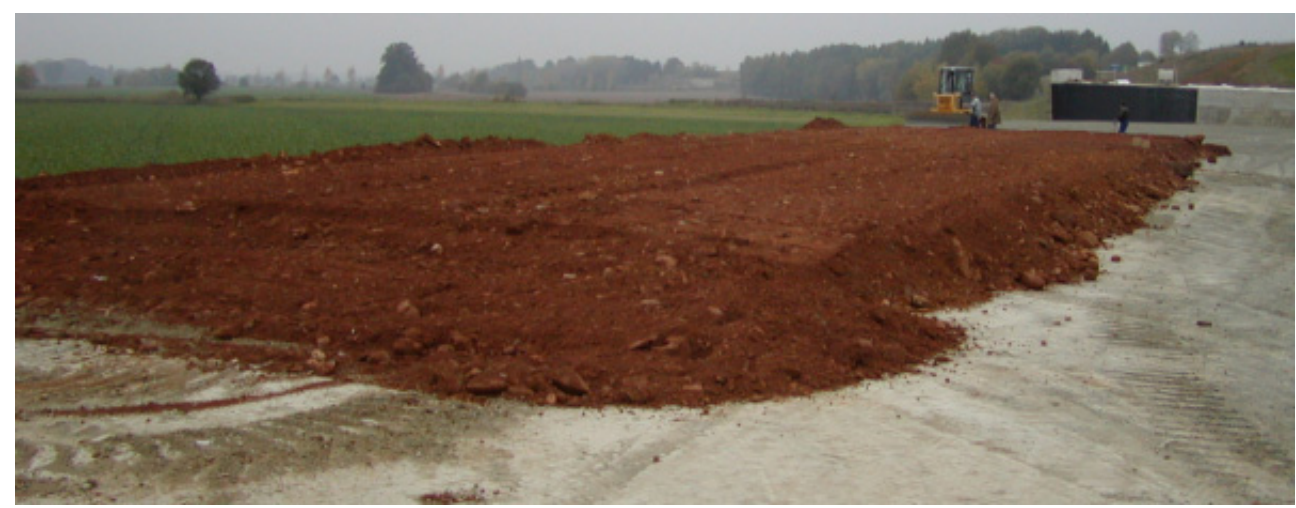

Fig. 4. View of the test field before experimental verification [2]

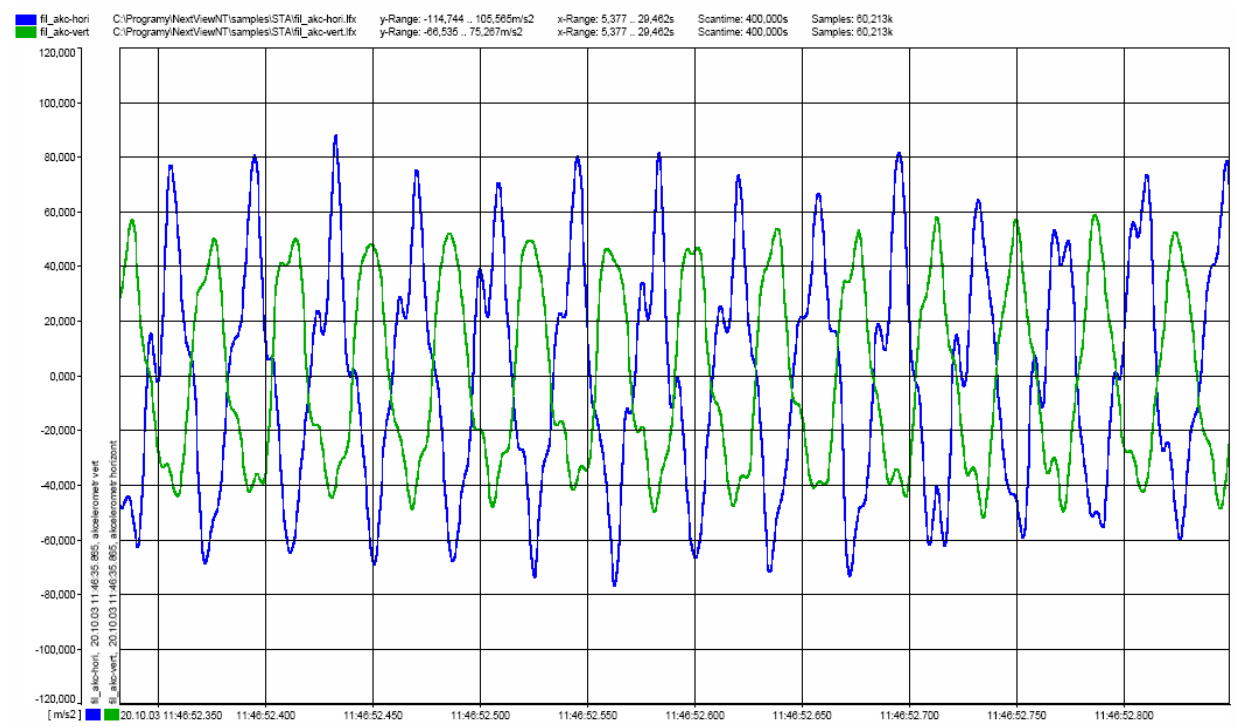

Fig. 5. Time course of the acceleration of the vibratory drum - vertical (green) and the horizontal (blue) [2]

Two aspects were observed in the evaluation. The visual inspection of the compacted surface and the deformation during the compaction process [1]. In addition, the measured values of the 
measured acceleration in the horizontal and vertical directions (Fig. 5) were evaluated in the defined locations marked by the position marker. The acceleration results were statistically processed (mean, median, standard deviation, see Table 1). Furthermore, the continuous calculations of the frequency spectrum of the measured accelerations during the vibrations trips were performed by FFT analysis (Fig. 6) in software. This analysis was performed on a similar principle and a similar approach as used in paper [6]. In addition, the paper contains statistical processing of the amplitudes in the frequency spectrum (deviation amplitude, frequency), analysis of the CMV and RMV soil state method and their statistical processing [4].

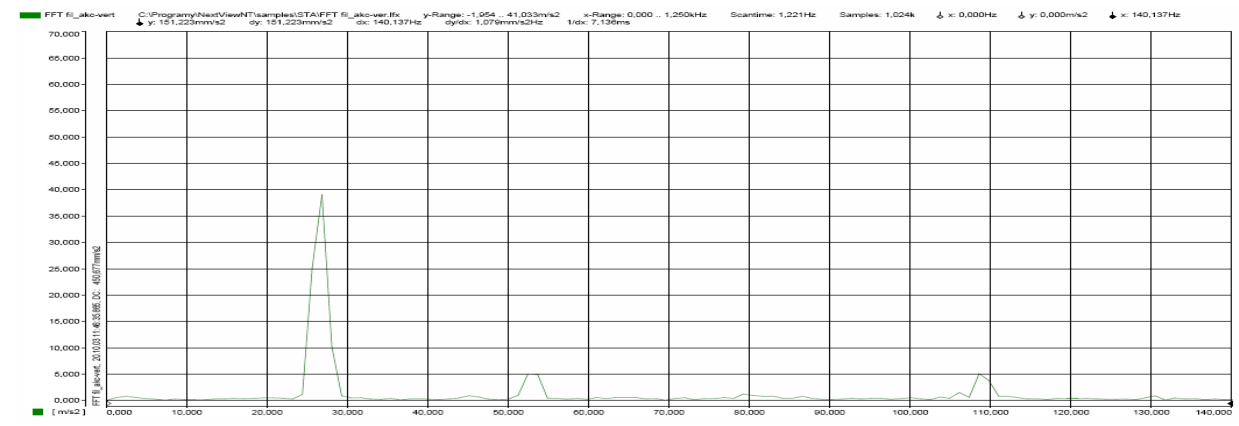

Fig. 6. FFT analysis of the vertical acceleration [2]

\section{The experiment evaluation example for field num. 6}

The appearance of the compacted field was a visually smooth surface in the direction of the trip (Fig. 7(a)), against the direction of the trip with a scaly effect (Fig. 7(b)). The acceleration values on the vibratory drum frame were measured to determine the interaction of the vibratory drum - soil (Fig. 6) [2]. These vertical and horizontal accelerations were evaluated according to the measured values (Table 1) and other parameters at the locations indicated by the marker measurement.

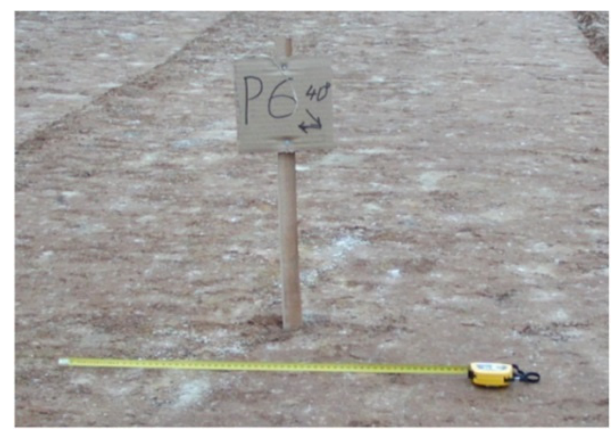

a)

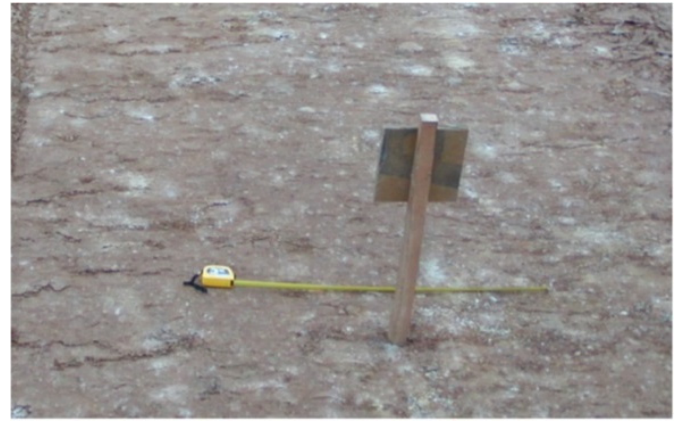

b)

Fig. 7. State of the surface of the compacted soil layer in field num. 6:

a) in the direction of trip, b) against the direction of the trip [2]

On the non-convex compaction slope $40^{\circ}$ of the vibratory exciter (Fig. 2(b)), the compaction intensity depth in the vertical and horizontal acceleration were lower than on the convex compaction. The CMV value (Table 1) indicates the state of the compacted layer to the depth in the vertical direction. The horizontal direction indicates the values for the action when smoothing the surface of the soil. 
Table 1. Measured values for the $40^{\circ}$ vibration exciter slope, non-convex compaction, statistical evaluation, field num. 6 [2]

\begin{tabular}{|c|c|c|c|c|c|c|c|}
\hline \multicolumn{2}{|r|}{ Quantity } & Value & Unit & \multicolumn{2}{|r|}{ Quantity } & Value & Unit \\
\hline \multirow{9}{*}{ ") } & Max $a_{\text {vert }}$ & 45,59 & M.s. ${ }^{-2}$ & \multirow{9}{*}{ 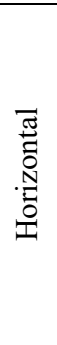 } & Max $a_{\text {hor }}$ & 52,5 & M.s. \\
\hline & Min $a_{\text {vert }}$ & 34,13 & M.s. ${ }^{-2}$ & & Min $a_{h o r}$ & 37,5 & M.s. \\
\hline & Median $a_{\text {vert }}$ & 40,88 & M.s. ${ }^{-2}$ & & Median $a_{h o r}$ & 46,65 & M.s. \\
\hline & Mean $a_{\text {vert }}$ & 40,11 & M.s. ${ }^{-2}$ & & Mean $a_{h o r}$ & 46,24 & M.s. ${ }^{-2}$ \\
\hline & Standard deviation & 3,072 & ${\mathrm{M} . \mathrm{s}^{-2}}^{2}$ & & Standard deviation & 3,172 & M.s. \\
\hline & Amplitude & 1,27 & $\mathrm{Mm}$ & & Amplitude & 1,51 & $\mathrm{Mm}$ \\
\hline & Frequency & 26,8 & $\mathrm{~Hz}$ & & Frequency & 26,8 & $\mathrm{~Hz}$ \\
\hline & $\mathrm{Cmv}$ & 17,95 & & & $\mathrm{Cmv}$ & 11,46 & \\
\hline & Rmv & 0,73 & & & $\mathrm{Rmv}$ & 1,42 & \\
\hline & Dry density & 2063 & Kg.m $\mathrm{m}^{-3}$ & & & & \\
\hline & Humidity & 4,8 & $\%$ & & & & \\
\hline
\end{tabular}

\section{Conclusions}

The behavior of the compacted system (vibratory roller - soil) was measured in each field at predetermined angles of gradient of the compaction force (Fig. 2).

From the measured values it can be concluded that the compaction intensity increases with the increasing slope of the compaction vector. At the same time the surface quality can be guaranteed by the convex compaction movement of the drum. These conclusions were supposed expected before the experimental verification. The benefit of the measurement was the possibility of verifying the behavior of the vibratory drum when in contact with the soil, which means between the slope of the vibration exciter $0^{\circ}$ to $90^{\circ}$.

The individual values of the CMV are not able to define any general conclusions about the value and intensity of the compaction. The comparison of the gradient values of CMV for the monitored space is important.

\section{Acknowledgement}

This work is an output of research Project "Development and Manufacture of Forwarder with a Special Emphasis on Environmental Cleanliness of Works and Efficient Biomass Processing in Forestry", Reg. No. TA04020087, Program to support applied research and experimental development "ALFA" by financial means from the Technology Agency of the Czech Republic.

The research leading to these results has received funding from Specific research Project of the Faculty of Mechanical Engineering, Brno University of Technology (FSI-S-17-4104).

\section{References}

[1] Anderegg R., Felten D. A., Kaufmann K. Compaction monitoring using intelligent soil compactors. GeoCongress 2006, Atlanta, Georgia, United States, 2006.

[2] Kašpárek J. Compaction Effects Optimizing of Vibratory Rollers. Vutium Brno, Brno, 2008, p. 1-124.

[3] Anderegg R. Non-Linear Vibration during the Dynamic Soil Compaction. Dissertation Thesis, VDI Verlag, Düsseldorf, 1998, p. 200.

[4] Brandl H., Adam D. The Dynamic Compaction Control of the Soil. Basic Research and Practical Application. Ministry of Transport, Innovation and Technology, Road Research, Procedia 506, Wien, 2000, p. 275.

[5] Briaud J. L., James R. W., Hoffman S. B. NCHRP Synthesis of Highway Practice 234: Settlement of Bridge Approaches. Transportation Research Board, National Reseach Council, Washington, D.C. p. 75-1997.

[6] Prokop A., Řehak K. Virtual prototype application to heavy duty vehicle gearbox concept. Engineering Mechanics Vol. 1, Issue 2017, 2017, p. 810-813. 